\title{
Jogos, patrimônio cultural e ensino de história
}

\author{
Games, cultural heritage and history teaching
}

\author{
Carmem Zeli de Vargas Gil* \\ Universidade Federal do Rio Grande do Sul \\ Bibiana Werle** \\ Universidade do Estado de Santa Catarina
}

Resumo A partir de dois jogos criados durante a disciplina de Estágio de Docência em História III - Educação Patrimonial realizada na Universidade Federal do Rio Grande do Sul, propomos, neste artigo, reflexões sobre o tema do patrimônio cultural na Educação Básica. Um dos referencias que inspira a escrita deste texto é Hartog (2014), que propõe pensarmos o patrimônio como uma das palavras mestras na compreensão de nossa relação com o tempo. Assim, situamos a utilização dos jogos como possíveis desencadeadores da discussão que problematiza a relação entre patrimônio cultural e memória na contemporaneidade, como também uma ferramenta didática que se torna cada vez mais presente no ensino de história.

PALAVRAS-ChAVE: Jogos; Patrimônio cultural; Educação.

Abstract Based on two games created during the subject of Teaching Internship in History III - Heritage Education, held at the Universidade Federal do Rio Grande do Sul (UFRGS), we propose in this article, reflections on the theme of cultural heritage in Basic Education. One of the referentials that inspired the writing of this text is Hartog (2014), which proposes that we think of heritage as one of the main words in understanding our relationship with time. Thus, we establish the use of games as possible triggers of the discussion that questions the relationship between cultural heritage and memory in contemporary times, as well as a didactic tool that is becoming more present in the teaching of history.

KEYWORDS: Games; Cultural heritage; Education. 


\section{Começa o jogo}

Este artigo discute o tema do patrimônio cultural e seu processo de ensino e aprendizagem através do uso de jogos como possibilidade para pensar o ensino de História enquanto campo de práticas criativas que problematizam as escolhas, os critérios e os grupos sociais envolvidos nas decisões do que pode ou não ser considerado patrimônio cultural brasileiro. $\mathrm{O}$ tema é atual na medida em que, nos últimos anos, proliferam-se publicações e materiais pedagógicos sob o lema Educar para Preservar - slogan que será problematizado neste texto. Ao mesmo tempo, é importante ampliar a publicação de experiências com jogos no ensino de História, considerando a necessidade de superar um modelo de aprendizagem tradicional (baseado na memorização, centrada na figura do professor e apenas em um conhecimento do passado) e utilizar atividades interativas que promovam aprendizagens cada vez mais significativas. Neste caso, "[...] os jogos têm sido recuperados como estratégias de transmissão/construção do conhecimento" (ANTONI; ZALLA, 2013, p. 150).

A inserção tanto dos jogos em sala de aula, como da elaboração dos mesmos a partir de conteúdos históricos pelos professores, oportuniza a performance dos estudantes por meio de uma ferramenta "capaz de absorver o jogador de maneira intensa e total" (HUIZINGA, 1980, p. 16), que lhes é historicamente usual fora do contexto escolar:

Com o seu longo histórico e ainda grande peso nas relações sociais contemporâneas, o jogo se faz presente no imaginário infantil. Seu uso como recurso pedagógico acaba por agenciar, de um lado, elementos da memória afetiva do estudante, estabelecendo pontes entre a experiência socialmente adquirida e os saberes formais e, de outro, apela à suas sensibilidades corporais e expressivas, oportunizando espaços de ação e criação (ANTONI; ZALLA, 2013, p. 151).

Autores como Huizinga, Caillois, Montessor, Piaget e Vygostsky estudaram os jogos como mediadores de aprendizagens e, com seus estudos, contribuíram para ampliar a compreensão sobre a importância dos jogos no desenvolvimento cognitivo. Johan Huizinga (2000, p.6) dedicou seu livro Homo ludens à caracterização do jogo, não apenas como parte integrante da cultura mas defende que a própria cultura possui um caráter lúdico. $\mathrm{O}$ autor questiona: "Por que motivo o jogador se deixa absorver inteiramente por sua paixão?”. A característica primordial do jogo reside exatamente nesta capacidade de fascínio que ele provoca. De acordo com o autor, a primeira característica fundamental do jogo é o fato de ser livre; uma segunda característica, é que o jogo é uma "evasão da vida "real" para uma esfera temporária de atividade com orientação própria". (p.10); a terceira característica é o isolamento e a limitação. "Possui um caminho e um sentido próprios" de tempo e espaço, pois enquanto "está decorrendo tudo é movimento, mudança, alternância, sucessão, associação, separação" (p.11). Assim, cria uma ordem, e é ordem para Huizinga. O jogo traz implícita a tensão, ou seja, o acaso, a incerteza; "o jogador quer que alguma coisa "vá" ou "saia", pretende "ganhar" à custa de seu próprio esforço” (p. 12). 
Giacomoni (2013, p.140) escreve um guia para a produção de jogos no ensino de História com ênfase nas dinâmicas de tabuleiro, onde fala do jogo como uma via de equilíbrio "entre o sério e a brincadeira, entre as regras e o acaso, entre os objetivos pedagógicos e o desejo do aluno, entre a indução do professor e a liberdade dos alunos". A proposta do guia e as reflexões apresentadas são construídas a partir da experiência de dois jogos: "Guerra Feudal" e "O Centralizador", aplicados com alunos da Educação Básica. Com a experiência destes jogos, o autor aponta possibilidades para desenvolver conceitos e conteúdos de História, indicando um percurso possível para que o professor possa elaborar jogos, destacando: a escolha da temática, os objetivos, a superfície da ação, a dinâmica, as regras e o layout.

$\mathrm{Na}$ experiência de ensino e aprendizagem abordada neste artigo, o convite ao leitor é pensar sobre a tríade patrimônio cultural,jogo e educação. A expressão "jogo" tem aqui o duplo sentido de nos fazer pensar, por um lado, na ambivalência de quem ganha e de quem perde no tabuleiro e, por outro, nas inclusões e exclusões próprias das políticas públicas voltadas ao patrimônio cultural que, ao selecionar os bens a serem preservados, elegem determinadas representações sobre o passado.

O texto a seguir divide-se basicamente em três tópicos: o primeiro propõe ideias sobre o jogo no contexto da educação; o segundo, discussões a respeito do patrimônio cultural como tema profícuo para o currículo da História na Educação Básica ou como tema transdisciplinar; e um terceiro apresenta duas experiências de jogos com o patrimônio. Nas conclusões, encerra-se a partida pensando as aprendizagens construídas pela experiência do jogo.

\section{Patrimônio cultural: o tema do jogo}

Inaugurada nos anos 1930, a legislação que pauta o patrimônio cultural brasileiro passou por modificações que também trouxeram novos olhares e diferentes interesses sobre o tema ao longo do século XX, até os nossos dias. Recorramos, portanto, aos documentos, marcos das políticas de patrimônio, para inicialmente conceituá -lo. A seguir, a definição de patrimônio histórico e artístico, conforme o Decreto-Lei que criava o órgão regulador Serviço do Patrimônio Histórico e Artístico Nacional (SPHAN) e o tombamento como instrumento de preservação, durante o primeiro governo Vargas, em 1937:

Art. $1^{\circ}$ Constitui o patrimônio histórico e artístico nacional o conjunto dos bens móveis e imóveis existentes no país e cuja conservação seja de interesse público, quer por sua vinculação a fatos memoráveis da história do Brasil, quer por seu excepcional valor arqueológico ou etnográfico, bibliográfico ou artístico (BRASIL, 1937, p. 24056).

Em 2000, é instituído o inventário e o registro dos bens imateriais, delimitados dentre um conjunto de saberes, celebrações, formas de expressão e lugares constituintes destas práticas. No ano de 2009, foi estabelecida a chancela da Paisagem Cultural Brasileira, baseada na conceituação de patrimônio cultural em relação à Constituição de 1988, que consolidaria a noção de bens intangíveis. A chancela da Paisagem Cultural representa um avanço conceitual na abordagem do patrimônio, já 
que considera não só valores materiais ou imateriais, mas a soma desses dois elementos na compreensão do que seja "porção peculiar do território nacional". Desse modo, o tombamento e o registro, assim como a chancela da Paisagem Cultural integram o rol de instrumentos de preservação do patrimônio cultural. Trata-se de três momentos que evidenciam o patrimônio como resultado de uma produção construída historicamente.

Da mesma forma que o historiador constrói passados a partir de vestígios, igualmente aprendemos a ver objetos como patrimônio cultural, a partir de uma operação de saberes e poderes. Assim, no primeiro momento da política de preservação, o patrimônio foi entendido como bem material excepcional alusivo a fatos históricos. Foram criadas instituições patrimoniais e legislação específica para cuidar do patrimônio com técnicos responsáveis por avaliar e selecionar o que preservar. No segundo momento, a continuidade histórica de práticas e formas de expressão aliada à representatividade para a memória nacional, conjuga os critérios para o registro como patrimônio. Também a chancela evidencia o entendimento mais amplo do conceito e, como bem lembra Canclini (1994), o patrimônio de uma nação vai muito além dos bens produzidos por grupos hegemônicos e reconhece a necessidade de abarcar, além das expressões das comunidades tradicionais, a produção cultural de operários e camponeses.

Trabalhar o patrimônio na escola é, então, colocar essas questões em debate na sala de aula, considerando as escolhas e os significados que cada grupo constrói para o patrimônio que os constitui. A perspectiva do patrimônio imaterial ressalta práticas sociais cotidianas, o que implica refletir sobre as vivências no lugar do acúmulo de informações como requisito para que os alunos acessem o conhecimento. Tais discussões podem contribuir para pensar a relação entre currículo e cultura, sendo esta entendida não somente como apreciar as artes ou a hierarquização em torno da palavra civilização. A palavra cultura implica o conjunto de práticas por meio das quais significados são produzidos e compartilhados em um grupo. $\mathrm{O}$ currículo expressa, também, práticas que propiciam a produção e o consumo de significados. Assim, em uma sociedade desigual a cultura é um terreno de disputas e o currículo é um espaço em que esse mesmo conflito se manifesta, não sendo somente saberes a serem transmitidos. É, sim, um lugar no qual, em meio a tensões, se produz e se reproduz cultura (MOREIRA; SILVA, 1997).

Se a História é, como afirma Chartier (2009), um modo de representação da experiência humana no tempo, como seu ensino pode contribuir para que os alunos, ao compreenderem os processos históricos, desnaturalizem visões, problematizem estereótipos e ampliem a compreensão do outro? Como observa Fernando Seffner (2012), a História, certamente, não é mais a mestra da vida, mas pode ser excelente conselheira, perturbando certezas.

A produção do patrimônio cultural não é uma operação inocente e a determinação dos bens culturais e de seu valor patrimonial se inscreve em um jogo político e histórico. Se a História não assumiu a vanguarda no debate e na definição de políticas de patrimônio, contudo, é da História que emergem narrativas acerca da nação e do 
passado que, mais tarde, se aproximam ou não das representações de Brasil, forjadas a partir das ações do SPHAN (atualmente IPHAN), desde os anos 1930. A construção de um patrimônio nacional no Brasil foi articulada à ideia de "uma" identidade para a nação, fazendo com que cada um se sentisse parte integrante da mesma. É do campo da História e de seu ensino debater tais processos, problematizando a produção do patrimônio como essencialmente boa. Ao contrário de propostas consensuais, cabe aos historiadores que se dedicam a uma educação voltada ao patrimônio cultural refletirem sobre o campo que o produz, desnaturalizando-o; problematizarem os processos históricos e sociais que o geraram, dessacralizando-o; distanciarem-se de uma perspectiva que oponha educadores e educandos como esclarecidos e não esclarecidos; e, por fim, compreenderem as ações de diversas instâncias que lidam com o patrimônio cultural enquanto produtoras e disseminadoras de saberes e visões sobre ele (GONÇALVES, 2014).

\section{Jogando com o patrimônio cultural}

Relativamente recente na formação acadêmica dos historiadores, o tema da preservação do patrimônio cultural insere-se na discussão historiográfica acerca da maneira como nos relacionamos com o tempo na contemporaneidade, caracterizada, conforme Hartog (2014), pelo presentismo. Para compreender esta relação primordial com o presente, Hartog (2014, p. 31) indica duas palavras mestras: memória e patrimônio, de modo a tratá-las como indícios, sintomas de uma relação com o tempo que se faz sentir acelerado, inseguro e, em razão disso, busca amparar-se no patrimônio, alter ego da memória, como um "convite à anamnese coletiva" (HARTOG, 2014, p. 195). Inspirado pelos acontecimentos do último século na Europa, Hartog localiza o regime de historicidade presentista como um momento de crise, no qual a ordem do tempo foi posta em questão por situações como as guerras mundiais e a queda do Muro de Berlim, por exemplo. A crença em um futuro baseado na ideia de progresso, pautada pelo moderno regime de historicidade, de acordo com Koselleck (2006, p. 314), foi abalada, de modo que o passado deixa de configurar-se como exemplo e o futuro mostra-se ameaçador. Assim, o presente torna-se o único campo de possibilidade e, combinado com o avanço tecnológico, recicla-se a todo o momento.

Verificamos, nesse sentido, que o tema patrimônio cultural está na ordem do dia, e é patente nas discussões historiográficas que o abordam, além da estreita relação do conceito com o regime de historicidade presentista, e tensões que envolvem questões como: o porquê de preservar um bem cultural; quais são os critérios e quem escolhe o que deve ser patrimonializado. Esses são questionamentos que auxiliam a compreensão e um olhar crítico sobre a maneira como nos relacionamos com o nosso tempo histórico e, nesse caso, traduzem indagações fundamentais a serem realizadas e pensadas em sala de aula. Como afirma Seffner (2013, p. 33), "Podemos afirmar que a aprendizagem mais significativa produzida pelo ensino de História, na escola fundamental, é fazer com que o aluno se capacite a realizar uma reflexão de natureza histórica acerca de si e do mundo que o rodeia”.

Discutir o tema do patrimônio cultural é, portanto, trabalhar com um assunto em voga no tempo presente, quando as demandas sociais não se furtam do olhar 
atento do historiador. As reivindicações pelo direito à memória de grupos anteriormente marginalizados do cenário político nacional, por exemplo, estão na ordem do dia, e não podem passar despercebidas no contexto escolar, onde os alunos, que são peças chaves da sociedade globalizada, necessitam compreender os processos históricos, e não apenas seus resultados.

A introdução, em sala de aula, dos jogos apresentados neste artigo tem como intenção fomentar a abordagem destas questões teóricas pelas quais o tema do patrimônio cultural perpassa, bem como se utilizar de uma ferramenta didática cada vez mais utilizada em aulas de história, na medida em que proporciona uma fruição do conteúdo - alinhando-se com a perspectiva de que nossos alunos são fruto desta sociedade cada vez mais dinâmica. Dessa forma, concordamos com Seffner (2013, p. 32), segundo o qual "[...] o ensino de história não pode estar preso a um livro didático, e funciona em forte articulação com as demandas do tempo presente".

Cotidianamente, o professor lida com diversas problemáticas em sala de aula, como a evasão, o desinteresse dos estudantes e a dificuldade de aprendizado, por exemplo. Transpor a mera definição de conceitos e possibilitar a quem aprende refletir e pensar historicamente sobre os mesmos não apenas é outro desafio, como também uma necessidade para a compreensão dos processos históricos que ensinamos. Em se tratando de patrimônio, lidamos com um daqueles conceitos que sabemos o que significa, mas é com dificuldade que conseguimos explicá-lo, e é a partir dessa noção que a utilização dos jogos aqui propostos auxilia a apreensão dessas questões (no próprio ato do brincar) em função de um "mundo imaginado":

\footnotetext{
Nesse ato de jogar, os estudantes estão na origem dos conceitos, pois que ali, no ato, conceitos históricos se gestam e passam a dar forma à vida, aos modos de vida, aos antigos presentes. [...] O jogo é o próprio ato. É brincar em ato, nem uma forma que antecede a brincadeira, nem um resultado esperado que se divida do próprio ato de brincar e, então, que ao se jogar, se instala no próprio ato criativo, na passagem de um "não-saber ao saber" (PEREIRA; GIACOMONI, 2013, p. 19).
}

Relacionar os patrimônios culturais registrados no Brasil aos seus espaços geográficos, aos grupos que se referem, bem como possibilitar chaves de compreensão da dinâmica em torno da maneira como é produzido o patrimônio cultural brasileiro são questões levantadas e possíveis de serem desenvolvidas durante o jogar do Patripife e do Agente Infiltrado. Os jogos procuram, sobretudo, não definir e nem dar respostas prontas acerca da temática, mas sim possibilitar a problematização acerca das tensões que envolvem a patrimonialização dos bens e dos processos históricos relacionados à sua constituição enquanto patrimônio ou não.

\section{Os jogos: Patripife e O Agente Infiltrado}

Patripife e O Agente Infiltrado são dois jogos que lançam mão do manejo de cartas e tabuleiro, respectivamente - objetos tradicionais que, na contemporaneidade, costumam ser deixados de lado e trocados pelo teclado do computador e o controle do videogame, opções que nem sempre são possíveis nas escolas públicas, onde 
a existência de computadores com tecnologia apropriada para a realização dos jogos é incomum. Confeccionados em sala de aula, Patripife e O Agente Infiltrado envolvem professores e estudantes como agentes no processo de produção dos materiais didáticos, que são fabricados com objetos encontrados em qualquer escola: papel, lápis de cor, tesoura e régua, por exemplo. Nos jogos aqui propostos, além de interagir coletivamente, o estudante é levado a expressar-se corporal e verbalmente no momento em que, ao descobrir uma nova carta, ao avançar uma "casa" no tabuleiro e, enfim, ao cumprir os objetivos de cada jogo, lhe é revelado um desfecho e, partir daí, outras questões podem ser debatidas em relação aos conteúdos escolares.

Para além da aprendizagem, em que através dos jogos os alunos reflitam sobre o tema do patrimônio cultural e o relacionem com a realidade cultural na qual estão inseridos, a disposição dos mesmos para a prática do Patripife ou do Agente Infiltrado no ambiente escolar permite um deslocamento das normas comportamentais estabelecidas na escola, como afirmam Pereira e Giacomoni (2013, p. 19):

[...] o jogo pressupõe uma entrega ao movimento absoluto da brincadeira e que jogar implica um deslocamento. Um deslocamento do espaço, da ordem, das medidas, dos horários, das imposições disciplinares, da avaliação, das provas, numa palavra, da obrigação.

Nos jogos anunciados a seguir, patrimônios materiais e os trinta e oito patrimônios intangíveis registrados pelo IPHAN são levados para o universo concreto dos alunos através de sua interação com as cartas do Patripife e o tabuleiro de O Agente Infiltrado, oportunizando, a cada trio de cartas formado, e a cada "casa" vencida no tabuleiro, novas conexões para a compreensão da constituição do patrimônio cultural. Enfatizamos, ainda, a ideia de que a realização dos jogos aqui anunciados deve ser considerada uma das diversas facetas possíveis no tratamento do tema do patrimônio cultural em sala de aula, necessitando, para sua validade, fazer parte de um processo mais amplo do planejamento escolar de cada professor.

\section{O Patripife}

Patripife é um jogo criado a partir de um tradicional jogo de cartas, o "pife", e objetiva relacionar a seguinte tríade: os patrimônios intangíveis brasileiros, as suas localizações geográficas e seus respectivos Livros de Registro. A associação entre essas três dimensões pelo estudante ao formar uma "trinca" requer um conhecimento prévio sobre o tema patrimônio cultural, bem como sobre a geografia brasileira, destinandose, dessa forma, para o público de alunos do Ensino Médio.

O jogo tem a intenção de ser um problematizador na reflexão acerca do conceito de patrimônio intangível e pretende a ponderação sobre o mesmo em dois momentos: antes do jogo - quando o professor faz uma explanação aos alunos e discute as tensões que envolvem o registro de um bem, como e por que preservá-lo, o porquê de sua escolha, o que ele diz sobre determinado grupo, quais são os bens obliterados - e durante a prática do jogo -, pois cada trinca formada pelo aluno é um conjunto de relações que formam a informação sobre determinado bem. 
O jogo inicia com a distribuição de nove cartas a cada participante, sendo que podem jogar até seis alunos por jogo. Como o tema de cada trinca é um dos trinta e oito patrimônios intangíveis registrados pelo IPHAN, totalizam-se 114 cartas. Cada trinca possui as seguintes características: 1 - a descrição de um dos trinta bens intangíveis registrados pelo IPHAN; 2 - o desenho de um mapa destacando a região em que o bem está localizado e informando a qual dos livros de registro o bem se refere; 3 - uma imagem do bem. $\mathrm{O}$ vencedor do jogo é aquele que formar três trincas primeiro e ficar sem cartas na mão, o vice-campeão é aquele que formar as trincas depois do vencedor, e assim por diante. Caso o professor sinta necessidade de incluir mais alunos no jogo, é possível dobrar o número de cartas, duplicando-se, assim, cada uma das trincas. Vejamos o exemplo de um conjunto de trinca: o ofício das paneleiras de goiabeiras.

Figura 1 - Exemplo de um conjunto de trinca.
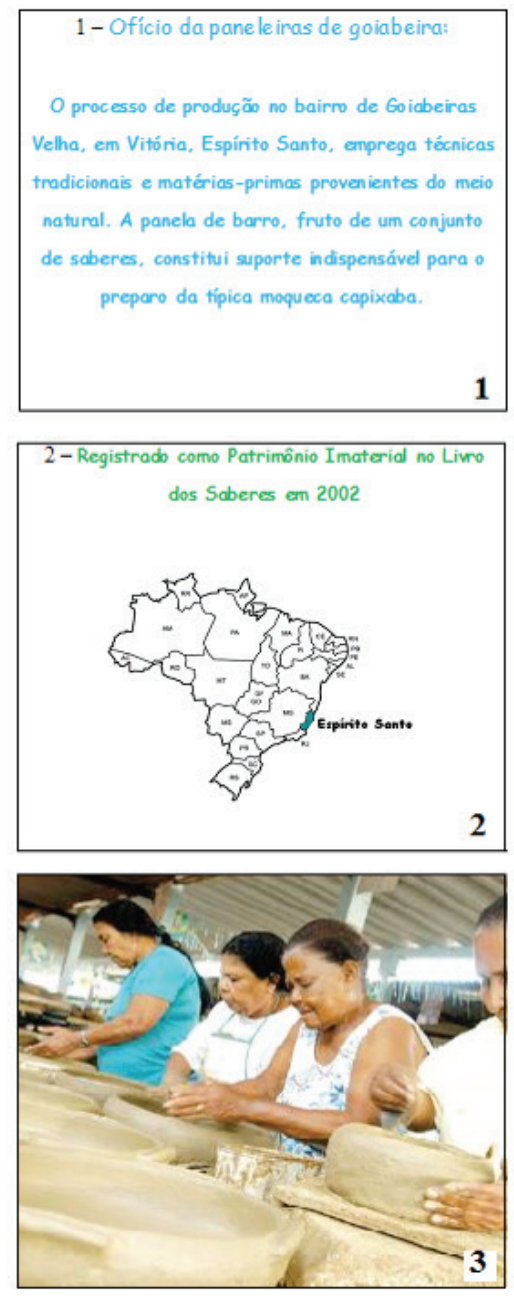

Fonte: imagens 1 e 2 autor do jogo, imagem 3 disponível em: <www.iphan.gov.br>. 
Outra faceta do jogo é a possibilidade que traz com as cartas "2" e "3", visto que a segunda carta possui um mapa do Brasil destacando a região referente ao bem algo que pode contar com a intervenção do professor de geografia - e a terceira carta, que contém uma imagem referente ao bem, de modo que permite ações educativas na área das artes, como a própria confecção das cartas do jogo. Outra possibilidade que emerge a partir do jogo é a criação de "Patripifes locais", ou seja, a criação de trincas, pelos alunos, que sejam referentes aos patrimônios culturais da comunidade em que habitam.

\section{O Agente Infiltrado}

Assim como o Patripife, O Agente Infiltrado é um jogo que proporciona, através da interação participativa entre os alunos, a apreensão do conteúdo de maneira ativa pelos mesmos. Valendo-se de um tabuleiro composto por dez "casas" que representam dez bens culturais brasileiros, e uma "casa" referente à sede do IPHAN, o jogo propõe um passeio pelos patrimônios presentes no tabuleiro a partir de um objetivo específico: os jogadores (chamados de agentes infiltrados) devem descobrir qual é o patrimônio que o jogador Régis T. Rei ("registrei") foi incumbido de analisar pelo IPHAN. Visualizamos, a seguir, o tabuleiro do jogo:

Figura 2 - Tabuleiro do Agente Infiltrado.

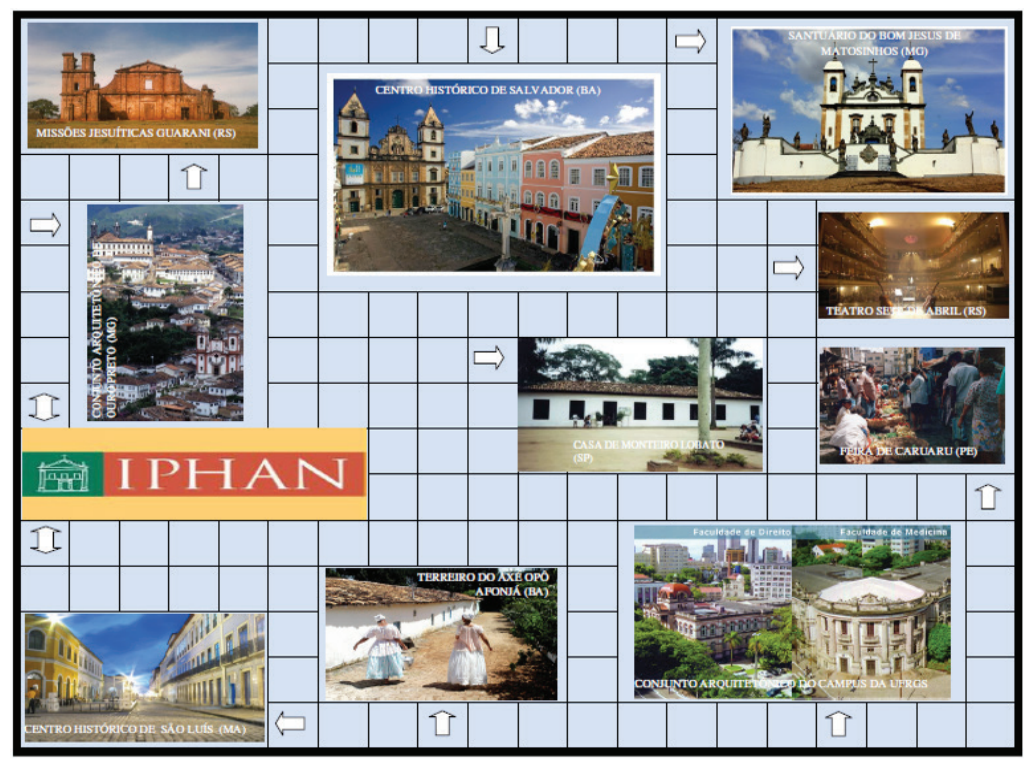

Fonte: autor do jogo.

O jogo, que pode contar com a participação de, no máximo, cinco alunos, inicia com o jogador selecionado para representar o agente Régis T. Rei, que tem como função impedir que os outros jogadores (agentes infiltrados) desvendam qual é o patrimônio a ser descoberto. Régis T. Rei pode bloquear determinados patrimônios presentes no jogo ao depositar a cartinha do IPHAN sobre eles. Dessa forma, o de- 
safio se torna ainda mais instigante para os agentes infiltrados que, se deslocando de "casa" em "casa" conforme o número obtido no lançamento do dado, entram nas "casas" relativas aos patrimônios e, a partir daí, terão acesso às cartinhas com as indicações que ajudam na resolução do desafio.

O jogador que desvendar o patrimônio retorna à casa inicial do jogo, a Sede do IPHAN, e responde às seguintes questões: qual é o bem, por que ele pode ser um patrimônio cultural brasileiro, e por que deve ser preservado. Além disso, recebe a tarefa de registrar ou tombar o bem, de acordo com a conclusão que chegou ao solucionar o desafio. Régis T. Rei atua como avaliador nesta etapa final, e confere se o patrimônio desvendado pelo agente infiltrado é realmente aquele ao qual foi incumbido de analisar pelo IPHAN. Caso a resolução encontrada pelo agente infiltrado não seja correta, o jogo continua e, se nenhum jogador descobrir o patrimônio, Régis T. Rei se torna o vencedor.

Segundo a criadora de O Agente Infiltrado, o jogo busca estimular a reflexão sobre o significado de um bem cultural, o que pode levar ao questionamento de quem o escolheu para consagrá-lo e, daí em diante, chegar à questão de qual grupo está representado em diferentes bens culturais. Assim como o Patripife, o Agente Infiltrado também pode ser produzido pelos alunos em sala de aula e, em vista disso, pode conter os patrimônios locais em sua composição. A confecção dos jogos estimula as discussões em torno da questão da seletividade presente nos bens culturais consagrados e, além disso, torna o conhecimento, possivelmente, mais concreto para os alunos.

\section{Termina a partida. E as aprendizagens?}

Jogar em sala de aula é uma estratégia interessante para acompanhar a aprendizagem e o interesse dos alunos. Em função de conterem desafios, mistérios, metas e interação com os colegas, os jogos têm componentes elementares que instigam alunos a alcançarem seus respectivos desfechos. De certa forma, mobiliza para a aprendizagem. A experiência apresentada tem relevância, primeiro porque os jogos foram construídos em uma disciplina de Estágio de Docência no Curso de Licenciatura em História, o que supõe a discussão do tema do patrimônio cultural e dos jogos na formação inicial do professor de história; segundo, pois sugere o estudo do tema na educação básica, em especial, a partir de uma abordagem ampla que considera o patrimônio imaterial, para além dos bens de "pedra e cal".

Trabalhar com jogos em aulas de História é uma estratégia que vem crescendo e, no caso apresentado, possibilitou discussões teóricas que envolveram as relações entre memória e história; patrimônio cultural e jogos nas aulas de História. Trata-se de práticas de celebrações, saberes, formas de expressões e lugares que têm o potencial de fomentar discussões, tanto sobre os jogos como estratégia de aprendizagem quanto do patrimônio como tema transversal no currículo. De maneira geral, o jogo ampliou as possibilidades de abordagem do patrimônio, instigando os alunos a questionar o conteúdo estudado: por que os bens registrados são estes? Que relação tem estes bens registrados com as atividades culturais existentes em suas comunidades? Esses questionamentos possibilitaram aos professores em formação desnaturalizar o patrimônio 
cultural como algo sacralizado, permitindo com que os mesmos retomassem a ideia de que os patrimônios culturais são eleitos por determinadas instituições e profissionais da área que, em outros tempos, estiveram ligados a diferentes concepções de passado politicamente mobilizadas.

Para além da desnaturalização e dessacralização acerca do que é reconhecido oficialmente como patrimônio cultural, a realização dos jogos também possibilitou uma discussão acerca daquilo que cada aluno compreendia como repertório cultural da comunidade em que vivia. Quando questionados sobre quais seriam as práticas culturais presentes num jogo que se referisse ao município de Porto Alegre, a discordância de opiniões entre os estudantes trouxe à tona o caráter seletivo e nada consensual presente nas políticas de registro dos bens culturais. Para, além disso, as tentativas de cada estudante justificar suas escolhas permeava a questão acerca da necessidade de estabelecimento de critérios para que as ações de patrimonialização sejam exequíveis - o que remetia a discussão para ao texto da legislação sobre o patrimônio cultural nacional e sua problematização no que tange aos parâmetros instituídos. A realização dos dois jogos foi, nas experiências aqui mencionadas, propulsora de um debate que insere o tema patrimônio cultural num processo histórico mais amplo que, muitas vezes, parte do tempo presente (o conhecimento das práticas culturais registradas), para a compreensão de como são eleitas e legitimadas ao longo da história.

A elaboração do Patripife e de O Agente Infiltrado, na medida em que são ferramentas pensadas para a didatização de um tema marcado por discussões teóricas, podem ajudar no ensino e aprendizagem do patrimônio cultural em sua relação com as questões da diversidade da cultura brasileira, e no estabelecimento de formas de compreensão do tempo histórico, pois a existência dos bens culturais sugere a dinamicidade das práticas culturais, cujos significados são dinâmicos. Outro aspecto a destacar diz respeito à importância de inseri-lo no currículo escolar buscando sensibilizar alunos e professores para memórias de diferentes grupos étnicos e sociais, dando visibilidade aos seus costumes, tradições e lutas pela afirmação de direitos.

O tema do patrimônio cultural é, também, potente para romper com uma perspectiva iluminista do ensinar e do aprender. É profícuo para propor a dúvida: por que as coisas são como são? Quem definiu os critérios de escolha? Por que estes bens e não outros? Quem está representado? Quem fica de fora? Educar para o patrimônio é, nessa perspectiva, problematizar e dessacralizar o acervo já constituído. Trata-se de questões pertinentes na formação do professor de história. Portanto, história, patrimônio e jogos formam uma tríade que, talvez, promova interessantes reflexões para pensar o ensino de história na complexa tarefa de pensar processos de patrimonialização. $\mathrm{Pa}-$ tripife e O Agente Infiltrado são jogos criados nessa perspectiva, constituindo-se em recursos que possibilitam aos estudantes questionar o patrimônio cultural não como algo dado, mas construído historicamente, passível de interesses dos diversos grupos que o forjaram e com importância para a constituição das identidades das comunidades que o instituíram. 


\section{Referências}

ANTONI, E.; ZALLA, J. O que o jogo ensina: práticas de construção e avaliação de aprendizagens em História In: GIACOMONI, M. P.; PEREIRA, N. M. (Org.). Jogos e Ensino de História. Porto Alegre: Evangraf, 2013. p. 148-166.

BRASIL. Decreto-lei no 25, de 30 de novembro de 1937. Organiza a Proteção do Patrimônio Histórico e Artístico Nacional. Diário Oficial, Rio de Janeiro, 6 dez. 1937. p. 24056.

CANCLINI, N. G. O Patrimônio Cultural e a Construção Imaginária do Nacional. Revista do IPHAN, Rio de Janeiro, n. 23, p. 94-115, 1994.

CHARTIER, R. A História e a Leitura do Tempo. Tradução de Cristina Antunes. Belo Horizonte: Autêntica, 2009.

GIACOMONI, M. P. Construindo jogos para o ensino de História. In: GIACOMONI, M. P.; PEREIRA, N. M. (Orgs.). Jogos e Ensino de História. Porto Alegre: Evangraf, 2013. p. 9-24.

GONÇALVES, J. Da educação do público à participação cidadã: sobre ações educativas e patrimônio cultural. Mouseion (UniLasalle), v. 19,2014, p. 83-97.

HARTOG, F. Regimes de Historicidade. Presentismo e Experiências do Tempo. Belo Horizonte: Autêntica, 2014.

HUIZINGA, J. Homo Ludens: o jogo como elemento da cultura. Trad. J. P. MONTEIRO. São Paulo: Perspectiva, 1980.

. Homo Ludens: o jogo como elemento da cultura. Trad. J. P. MONTEIRO. São Paulo: Perspectiva, 4a edição, 2000.

KOSELLECK, R. Futuro Passado - contribuição à semântica dos tempos históricos. Rio de Janeiro: Contraponto, 2006.

MOREIRA, A. F.; SILVA, T.T. (Orgs.). Currículo: questões atuais. Campinas: Papirus, 1997.

PEREIRA, N. M.; GIACOMONI, M. P. Flertando com o Caos: os jogos no Ensino de História. In: GIACOMONI, M. P.; PEREIRA, N. M. (Org.). Jogos e Ensino de História. Porto Alegre: Evangraf, 2013. p. 9-24.

SEFFNER, F. Comparar a Aula de História com Ela Mesma: valorizar o que acontece e resistir à tentação do juízo exterior (ou uma coisa é uma coisa, outra coisa é outra coisa). Historiæ, Rio Grande, v. 3, n. 1, p. 121-134, 2012.

. Aprender e Ensinar História: como jogar com isso? In: GIACOMONI, M. P.; PEREIRA, N. M. (Org.). Jogos e Ensino de História. Porto Alegre: Evangraf, 2013. p. 25-46.

* Professora doutora da Universidade Federal do Rio Grande do Sul, Porto Alegre, Rio Grande do Sul, Brasil.

** Doutoranda em História pela Universidade do Estado de Santa Catarina, Florianópolis, Santa Catarina, Brasil.

\section{Correspondência}

Carmem Zeli de Vargas Gil - Universidade Federal do Rio Grande do Sul, Faculdade de Educação. Rua: Av. Paulo Gama, s/n - Prédio 12.201, Centro, CEP: 90046-900 - Porto Alegre, Rio Grande do Sul - Brasil.

E-mail: carmemz.gil@gmail.com - bibiwerle@gmail.com

Recebido em 08 de abril de 2015

Aprovado em 12 de abril de 2016 